\title{
A Comparative Study: Taxonomy of High Performance Computing (HPC)
}

\author{
Ranjit Rajak \\ Department of Computer Science \& Applications, Dr. Harisingh Gour Central University, Sagar (M.P), India
}

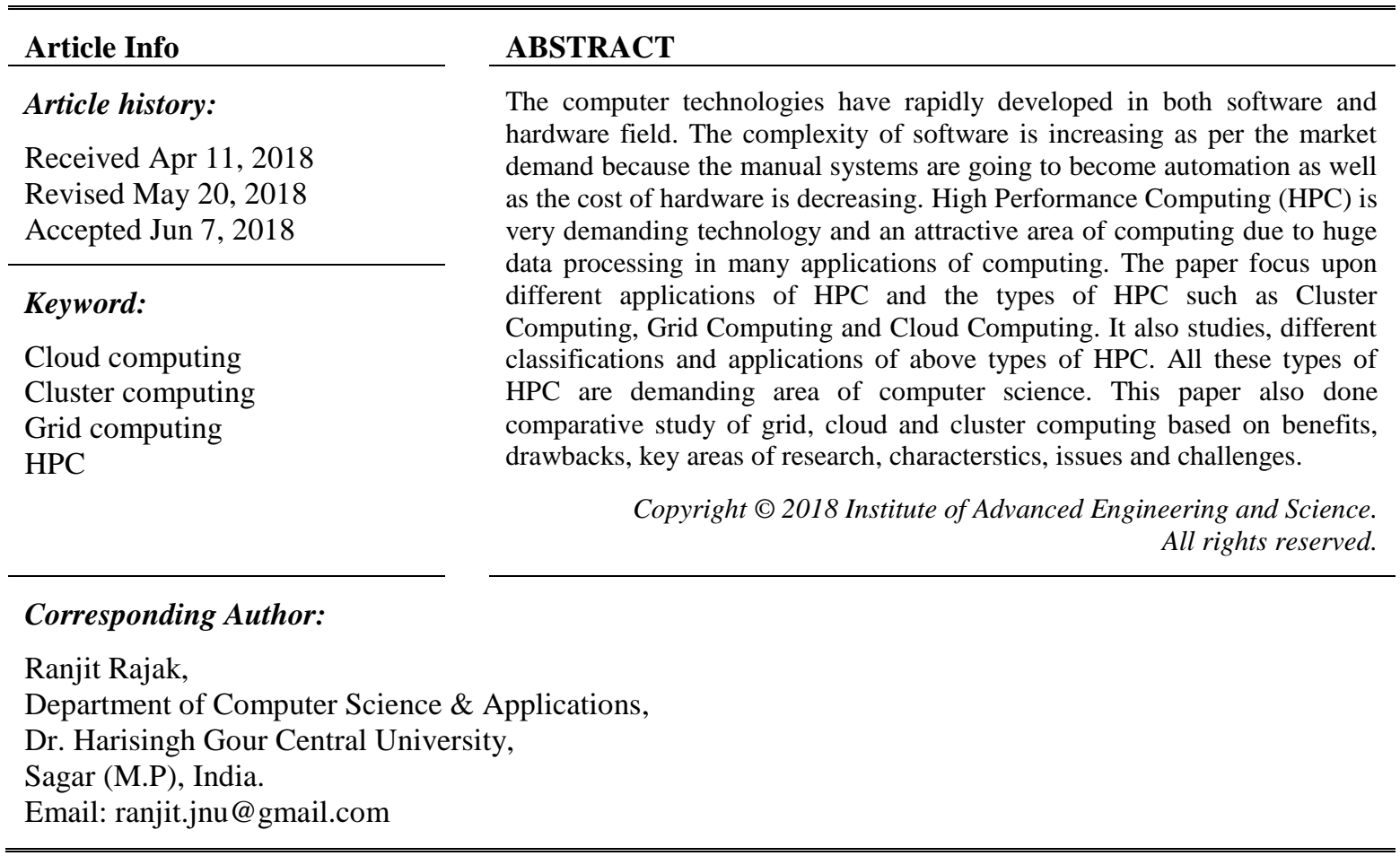

\section{INTRODUCTION}

High Performance Computing (HPC) is an attractive computing field in computer science and by using HPC, many application can be solved from engineering to scientific problems that were not easily solved by an conventional system. It is used in many applications such as molecular biology and genetic engineering, Space exploitation and cosmology, financial modeling and commerce, machine intelligent and cryptography and many more areas. The HPC is broadly classified into three categories namely Cluster Computing, Grid Computing and Cloud computing. Cluster Computing is a computing system in which two or more autonomous systems are connected to each other that solve a complex problem.

Grid Computing is like distributed computing in which resources are distributed locally or remote areas and it can be accessed by a desktop user or by a simple user as per demands. It basically follows that distributed computing principles and ideas. Cloud computing is also known as internet based computing due to rapid changes of technologies either hardware or software. Most of the users want to store data on cloud due to fast accessibility which also reduces the cost of various applications.

The detailed discussion on classification of HPC will be come in subsequent sections. Section 1 discussed about brief introduction of HPC and their classification, and Section 2 will be discuss of taxonomy of HPC in details. The comparative study of HPC taxonomy is done in the Section 3 and Section 4 will be the conclusion part the paper.

\section{CLASSIFICATIONS OF HPC}

This section provides the various types of HPC classification and their brief introduction. The HPC is classified into three parts: Cloud Computing, Grid Computing and Cluster Computing. 


\subsection{Grid computing}

It is a kind of HPC and is widely used in many areas of scientific research area where huge information are transmission. Grid computing is similar to distributed computing in which information are stored and accessed from/ in different multiple locations. The primary objectives of grid technology [1] are use of system resources, decentralized the system and interconnected the systems. Grid computing [2] provides reliable, uniform and seamless access to distributed resources. It is also called network -distributed parallel processing and large scale cluster computing [3]. According to IBM [4], [5] definition : A grid is a collection of distributed computing resources over a local or wide area network, that appear to an end user or application as one large virtual computing system. To create virtual dynamic organization [6] is the major vision of grid computing. This virtual dynamic organization is created through secure, resource management and sharing it among individuals and institutions. It is popular day by day due to it composed of multiple servers that are bound together and find solution of a given problem. Sharing, collecting, hosting and giving services to various end users are the main concerns [7] of grid computing.

Figure 1 shows the basic architecture of grid computing in which jobs are distributed onto the processors and grouped together. By using this model, maximum efficiency can be attained. Here, large number of jobs are executed only through network. It is also called as grid of computer system. This network is of very high speed and connected within grid. The primary job of gird resource broker [6] is to pool job and distribute across the server. There are two basic works of SAN, firstly it pools job requests and then allocated to the available processors. There are following key functional requirements [6] in grid environment:

a. Service Management: It provides fast response from the grid for any query that is generated by the users and applications.

b. Security Management: It protects or ensures the unauthorized access to grid resource from outside the domains.

c. Data Management: The primary duty of this management is transporting, cleaning and processing of the data between the nodes in grid environment.

d. Resource Management: It keeps the information of grid resource such as allocation and de-allocation of resources.

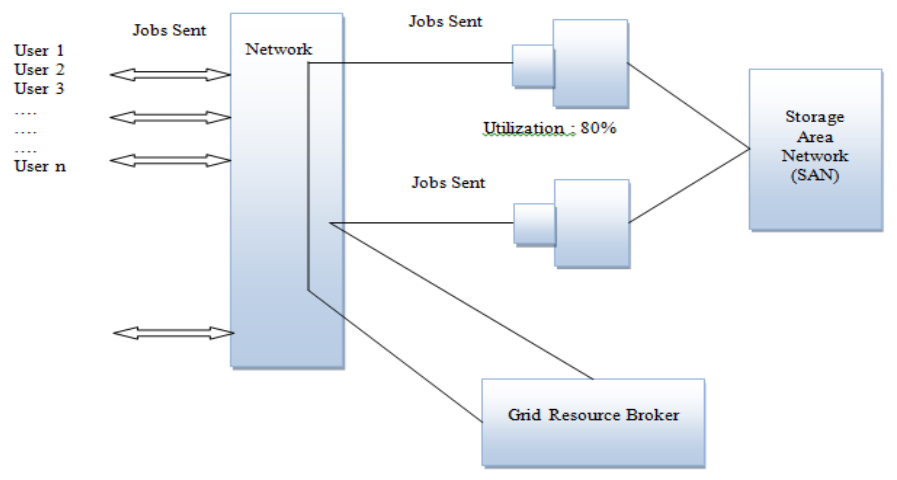

Figure 1. The basic architecture of grid computing in which jobs are distributed onto the processors and grouped together

\subsection{Cluster computing}

Technologies are dynamics in nature, and they are changing as per the market demands. Here it can be both software technology and hardware. The complexity of software increasing and cost of hardware is decreasing time to time. The introduction of cluster have been developed due low cost of hardware which consists multiple low cost computers and interconnected to each other and synchronous their work. The cluster computing is popular and attractive area due to the following factors: economic, performance, and flexibility. These factors make cluster computing more attractive.

a. The basic reason for popularity of clusters includes the improvement interconnection network technology and availability of high performance desktop computer.

b. There are number of formal definitions of a cluster computing given by multiple authors:

c. Definition 1 [8]: A cluster is two or more independent computers that are connected by a dedicated network to perform a joint task 
d. Definitions 2 [9]: A cluster is groups of servers that coordinate their actions to provide scalable, high available services

The Figure 2 shows the architecture of cluster computing [10]. This architecture consists of a large number of nodes or computer nodes. Each node has single processor or multiprocessors, memory, I/O and Operating System. A cluster consists of two or more computer nodes are interconnected via high speed LAN. This interconnected cluster system appears as single system for users and applications.

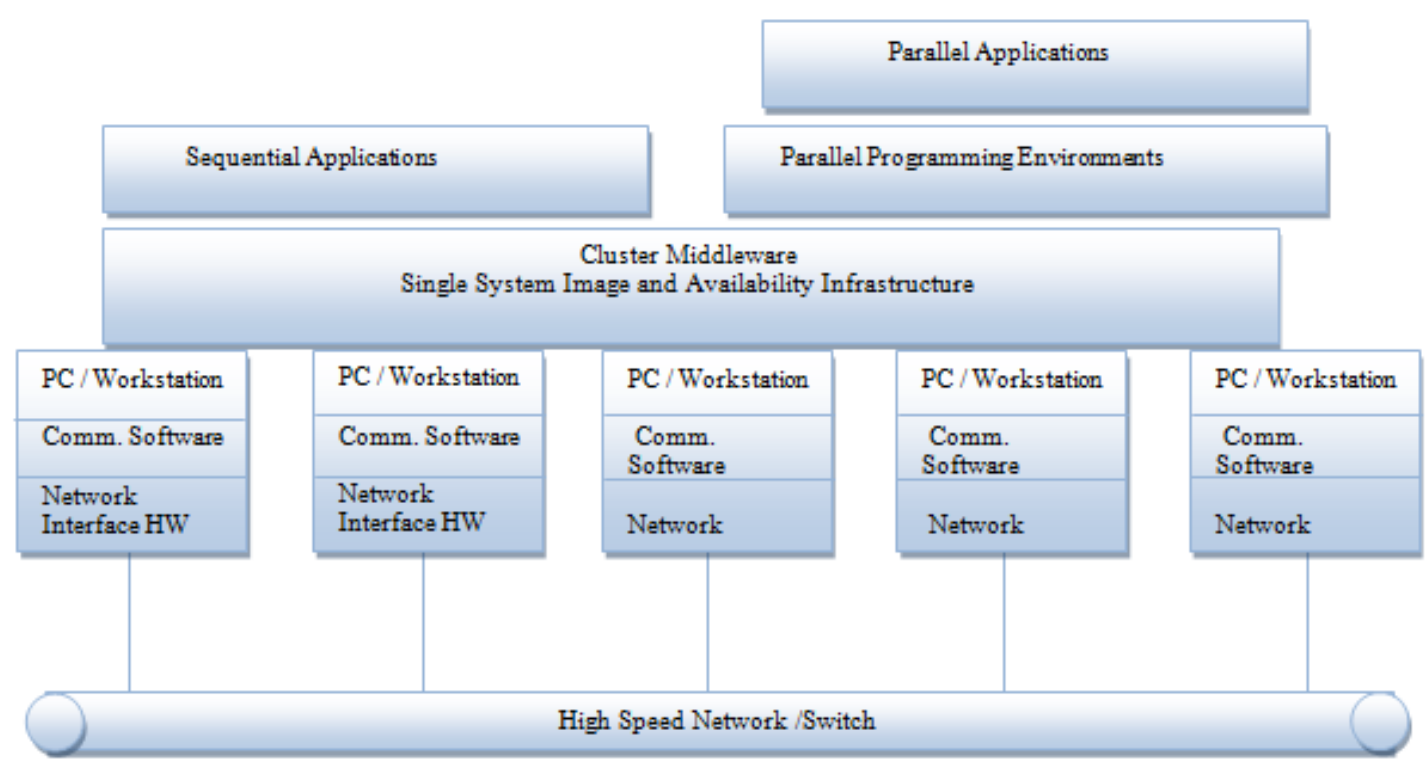

Figure 2. Architecture of Cluster Computing [10]

The most important and essential component of a cluster computing architecture is cluster middleware which provides single system view to the users. The cluster middleware provides three basic functionalities [6]: to support single system image, system availability infrastructure and resource management and scheduling. It is also a responsible for offering an illusion of a unified system images and availability out of a collection on independent but interconnected nodes.

\subsection{Cloud computing}

For past few years the computers are used for computing purpose by the end user. As the technology has changed rapidly and the cost of hardware has decreased and this makes the user of computing also increased i.e. the use of mobile devices like laptop, i-pad, palmtop also increased up to millions of the users. The computing using mobile device is the faster and easier than conventional approaches. The major problem using mobile devices computing is related to the life of battery and the storage. To overcome this problem, the cloud computing [11] have been introduced in recently. The cloud computing is defined as combination of virtualization and different computing resources that can be used by end users as per their requirements. The requirements are followed a principle i.e. pay per uses basis [12] computing resources.

Buyya has defined Cloud Computing as follows: "Cloud is a parallel and distributed computing system consisting of a collection of inter-connected and virtualized computers [13]. The cloud computing permit the end user to share the storage, computing resources and also provide the infrastructure. It has two important features [11]: Abstraction and Virtualization.

Abstraction means to collect information from developers and end user, the information consists of the detail information of implementation of the system. Virtualization is defined as sharing and pooling resources by the applications as shown in Figure 3. 


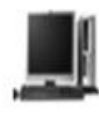

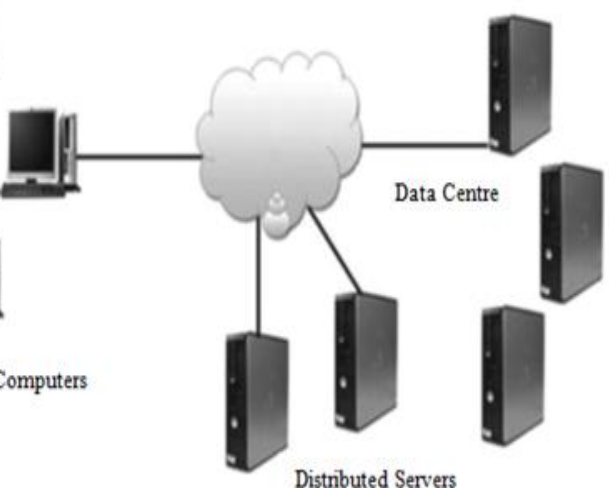

Distributed Servers

Figure 3. Components of Cloud Computing [14]

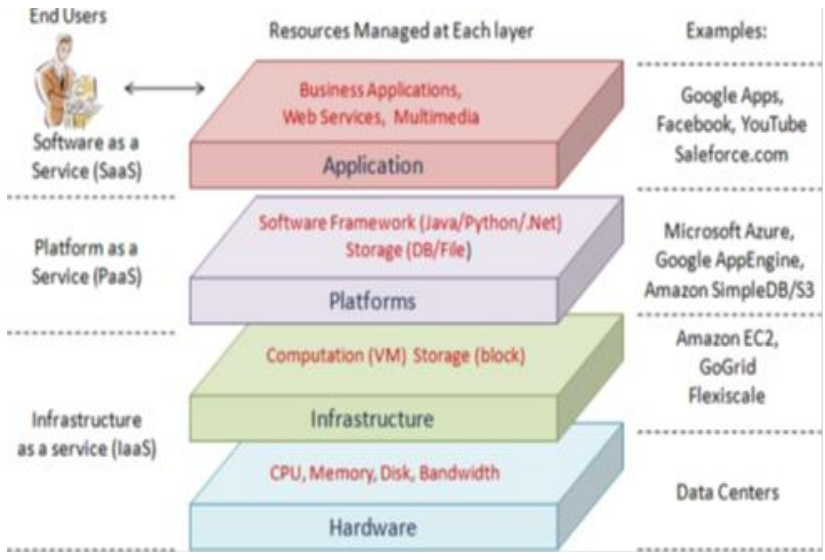

Figure 4. Cloud Computing Architecture [15]

These are the following components [14] consist cloud computing:

a. Client computers are the devices through which end user interact with cloud and manage the information on it. These clients are classified into three types: mobile, thin and thick clients. Mobile clients having example of Smartphone such as iPhone. Thin client having no internal hard drive and it depends on server for all work. Thick client is regular computer whose main work is to connect the cloud using web browser such as Google Chrome, Firefox or Internet Explorer.

b. Data Centre is the second component of the cloud computing that can be defined as the collection of servers where the applications to which the customers subscribe.

c. Distributed Server is the backbone of any cloud computing system.

Cloud computing architecture shows in Figure 4. The cloud computing architecture [15] is divided into four layers as namely:

Hardware layer: This layer is responsible for managing the physical resources of the cloud, including physical servers, routers, switches, power and cooling systems.

Infrastructure layer: Also known as the virtualization layer, the infrastructure layer creates a pool of storage and computing resources by partitioning the physical resources.

Platform layer: Built on top of the infrastructure layer, the platform layer consists of operating systems and application frameworks. The purpose of the platform layer is to minimize the burden of deploying applications directly into VM containers.

Application layer: At the highest level of the hierarchy, the application layer consists of the actual cloud applications.

\section{COMPARISONS OF TAXONOMY HPC}

Table 1 shows benefits and drawbacks of grid, cluster and cloud computing. Table 2 shows key areas of grid, cluster and cloud computing. Table 3 shows characteristics of grid, cluster and cloud computing. Table 4 shows issues and challenges of grid, cluster and cloud computing.

Table 1. Benefits and Drawbacks of Grid, Cluster and Cloud Computing

\begin{tabular}{|c|c|c|}
\hline Type of HPC & Benefits & Drawbacks \\
\hline Grid Computing [16] & $\begin{array}{ll}\text { - } & \text { Res ource Balancing } \\
\text { - } & \text { Access to additional res ource } \\
\text { Reliability }\end{array}$ & $\begin{array}{ll}\text { - } & \text { Not stable } \\
\text { High Internet connection } \\
\text { required } \\
\text { - Different administrator } \\
\text { domains }\end{array}$ \\
\hline Cluster Computing[16] & $\begin{array}{ll} & \text { Manageability } \\
\text { - } & \text { Single System Image (SSI) } \\
\text { High Availability }\end{array}$ & 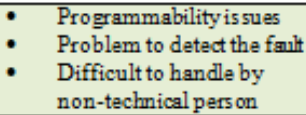 \\
\hline Cloud Computing $[16,17]$ & $\begin{array}{ll} & \text { Super computing power } \\
\text { - } & \text { High res ources availability } \\
\text { - } & \text { Virtualization } \\
\text { - } & \text { Frash recovery } \\
& \text { Flexibility }\end{array}$ & $\begin{array}{ll}- & \text { Less Reliability } \\
- & \text { Internet required } \\
\text { - } & \text { Non-interoperability }\end{array}$ \\
\hline
\end{tabular}


Table 2. Key Areas of Grid, Cluster and Cloud Computing

\begin{tabular}{|c|c|}
\hline Type of HPC & Key Areas \\
\hline Grid Computing[16] & $\begin{array}{l}\text { - } \text { Predictive Modeling and Simulations } \\
\text { - } \\
\text { - } \text { Medical and Military Research } \\
\text { - Energy Res ource Exploration } \\
\text { - Visualization }\end{array}$ \\
\hline Cluster Computing[16] & $\begin{array}{l}\text { - Educational Res ources } \\
\text { - } \quad \text { Medical Research }\end{array}$ \\
\hline Cloud Computing[16] & $\begin{array}{ll}\text { - } & \text { Banking Sector } \\
\text { - Weather Forecasting } \\
\text { - } & \text { Insurance Sector } \\
\text { Space Exploration }\end{array}$ \\
\hline
\end{tabular}

Table 3. Characteristics of Grid, Cluster and Cloud Computing

\begin{tabular}{|c|c|}
\hline Type of HPC & Basic Characteristics \\
\hline Grid Computing[18] & $\begin{array}{ll} & \text { Large scale } \\
\text { - } & \text { Geographical distribution } \\
\text { - } & \text { Heterogeneity } \\
\text { - } & \text { Resource sharing } \\
\text { - } & \text { Res ource Co ordination } \\
\text { - } & \text { Transparent access }\end{array}$ \\
\hline Cluster Computing[10] & $\begin{array}{l}\text { - High Performance data storage } \\
\text { - Distribute and Schedule Single System Image } \\
\text { - Loosely couple system }\end{array}$ \\
\hline Cloud Computing[14] & $\begin{array}{ll}\text { - } & \text { Broad Network Access } \\
\text { - } & \text { Rn-demand self service } \\
\text { - } & \text { Rapid Scalability } \\
\text { - } & \text { Elasticity } \\
\text { - } & \text { Measured Services } \\
\end{array}$ \\
\hline
\end{tabular}

Table 4. Issues and Challenges of Grid, Cluster and Cloud Computing

\begin{tabular}{|c|c|}
\hline Type of HPC & Issues and Challenges \\
\hline Grid Computing[19] & $\begin{array}{l}\text { - Sharing of Applications andData } \\
\text { - User-friendlyEnvironment } \\
\text { - }\end{array}$ \\
\hline Cluster Computing [17] & $\begin{array}{ll}\text { - } & \text { Middleware } \\
\text { - } & \text { Program } \\
\text { - } & \text { Elasticity } \\
\text { - } & \text { Scalability }\end{array}$ \\
\hline Cloud Computing[15] & 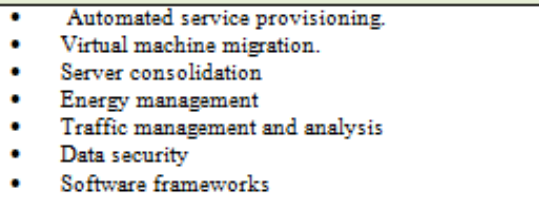 \\
\hline
\end{tabular}

\section{CONCLUSION}

The Fastest development of technologies and Internet speed, the resources for computing become less expensive, easily accesible and powerful for end user. The taxonomies of High Performance Computing (HPC) is from grid computing, cluster computing to the latest computing such as cloud computing. Cloud computing is the latest technology which provides Internet based Computing, less expensive and provides fastest web service at lower cost as compared to grid and cluster computing. This paper highlights various aspects of HPC taxonomy based on benefits, drawbacks, area of research, issues and challenges.

\section{REFERENCES}

[1] Zahra Pooranian, et al., "Independent Task Scheduling in Grid Computing Based on Queen-Bee Algorithm", IAES International Journal of Artificial Intelligence (IJ-AI), vol. 1, no. 4, Dec 2012, pp. 171-181. 
[2] Nidhi Jain and Inderveer Chana, "Energy Efficient and High Performance Scheduling Algorithm for Grid Computing", International Journal of Cloud Computing and Services Science (IJ-CLOSER), vol. 3, no. 3, pp. 179-188, June 2014.

[3] www.outervillage.com//content/grid_computing.

[4] Hawak, T., "Remark on Grid Computing", Planet Conference and Expo, San Jose, California, June 2002.

[5] Zhang, L,J., et al., "Developing Grid Computing Applications", Part 1: Introduction to Grid Architecture and Toolkit for Building Grid Solution, IBM Corporation, 2002,www.ibm.com

[6] C.S.R Prabhu, "Grid and Cluster Computing "PHI Publications, Feb. 2014.

[7] Gandotra Indu, et al., "Cloud Computing over Cluster, Grid Computing: a Comparative Analysis", Journal of Grid and Distributed Computing, Vol. 1, no. 1, pp. 1-4, 2011.

[8] Dilek Demivel, "High Performance Computing: Cluster Architecture".

[9] Zhang, Y. H Guo, W. Gao, "Research on Load Balancing on Multi Cluster Architecture Based on Business Component Partition", IEEE Proc. Of $3^{\text {rd }}$ International Conference on Information Technology and Application, 2005.

[10] Rajkumar Buyya, "High Performance Computing”, Architecture and System, vol. 1, PHI 1999.

[11] Cloud computing by V.K.Pachghare, PHI, 2016.

[12] R. Buyya, et al., "Cloud Computing: Principles and Paradigm", John Wiley \& Sons, Hoboken, NJ, 2010.

[13] Bhaskar Prasad Rimal and Ian lump, “A Taxonomy and Survey of Cloud Computing System”, 5th International Joint Conference on INC, IMS and IDC, pp. 44-51, 2009.

[14] Mobile Cloud Computing: Architecture, Algorithms and Applications, Debasis Dey, CRC Press, Taylor and Fracise Group, Edition 2016.

[15] Qi Zhegen, "Cloud Computing: State-of-the-art and Research Challenges", Journal of Internet Service Applications, Vol. 1, pp. 7-18, 2010.

[16] Kiranjot Kour and Anjandeep Kour Rai, "A Comparative Analysis: Grid, Cluster and Cloud Computing", International Journal of Advanced Research in Computer and Communication Engineering, vol. 3, no. 3, March 2014.

[17] Mohammad Alamgeer and Iqrar Ahmad, “Cloud Computing: Is a Step Ahead?”, International Journal of Computer Applications (0975 - 8887), vol. 159, no. 5, February 2017.

[18] Ayushi Pathak and Nisha Kaushik, "Grid Computing Issues, Challenges, Need and Practice", International Journal of Engineering and Computer Science, ISSN: 2319-7242, vol. 2, no. 4, pp. 853-863, April 2013.

[19] Manoj Kumar Mishra, et al., "A Review and Classification of Grid Computing Systems", International Journal of Computational Intelligence Research, ISSN: 0973-1873, vol. 13, no. 3, pp. 369-402, 2017.

\section{BIOGRAPHY OF AUTHOR}

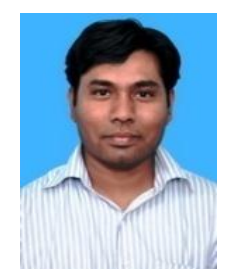

Dr. Ranjit Rajak is working as an Assistant Professor in the Department of Computer Science and Applications, Dr.Harisingh Gour Central University, Sagar (M.P).He has obtained the degree of MCA (2007), M.Tech (2009). In Computer Science and Technology, and Ph.D.(2014) in Computer Science and Technology from Jawaharlal Nehru University, New Delhi, India. His research interest lies in the area of Parallel Computing, Scheduling Problem, and Cloud Computing. He has published over 11 papers in the journals of international repute. He is a member of IAENG and CSI. 